\title{
Perspectives of Instructional Staff of Cohort Learning Groups
}

\author{
Clive Hickson \\ University of Alberta \\ Canada
}

\begin{abstract}
In recent years, the importance of developing student learning communities in post-secondary settings has received considerable attention. This has led many researchers to investigate the perspectives that students have of participating in such cohort groupings. Much of collected understanding has, from the student perspective, been supportive of such learning experiences. However, comparatively little understanding has been gained of the perspectives of the instructional staff members that work with these student learning groups. Therefore, in order to complete the circle of understanding that encompasses the perspectives of both students and instructors, gathering the perspectives of instructional staff can enhance the overall insight of this type of learning experience. This paper describes a research project that, through the utilization of action research methodology, systematically investigated, gathered information about, and attempted to improve ways of operation with instructional staff in a cohort learning community experience. The findings from the data indicated that the participants valued their experiences of working with a cohort learning group and believed that both they and students benefitted from the experience. From the data, three major themes were identified that indicated the need for instructional staff to: understand the importance of developing the potential of the cohort learning community; foster opportunities for communication between instructors; and, recognize themselves as their own cohort community.
\end{abstract}

\section{Introduction}

In the 1980s, post-secondary institutions began to follow a "business model" approach to their operations [1]. This change of approach resulted in administrators being faced with the increased challenge of not only managing large scale environments but also doing so while being efficient and financially creative.

This was not a simple challenge to undertake as administrators were faced with environments that often incur considerable costs and, at the same time, ensuring high quality educational experiences [2]. Notably, this period was also accompanied by a rise in the popularity of undergraduate education programming and student demand for quality learning experiences. Therefore, the effectiveness of instructional delivery became an important point of interest for institutional administrators [3].

The trend of popularity of undergraduate education and demand for high quality student experience has not decreased in recent years and, in many respects, has increased. This kind of "client pressure" created the need for institutional administrators to investigate different programming options that could serve to be cost-effective and also support the continued development of instructional excellence in order to ensure high quality learning opportunities for students [2].

\section{Related Literature}

At the same time that institutional administrators were starting to consider how to address financial and student interest challenges, the demand for highquality student life experiences also began to emerge from prospective students. This demand created an additional layer of consideration for administrators to undertake in order to meet the changing needs of their prospective and current student body.

\subsection{Student support}

The notion of feeling supported is a basic human need and, arguably, can influence success or failure. A considerable amount of research was conducted in the 1980s and 1990s that investigated the impact of "loneliness" and student need for "belonging" [4]. This research identified that loneliness and the need to feel a sense of belonging can exist within every age grouping but appeared to be particularly prevalent with adolescents and young adults and has become common problem for many post-secondary students [4].

Critically, loneliness has been found to contribute to a wide-ranging set of negative feelings and a lack of sense of self, feelings of anxiety, low self-esteem, and hopelessness [4]. These feelings can be especially prevalent when students are navigating the hallways of post-secondary institutions for the first time $[4,5]$ and can impact student retention and success [5]. Finding ways to address a sense of belonging in students to negate any feelings of 
loneliness is an important issue that post-secondary institutions face [5].

\subsection{Learning communities}

In regard to learner experiences at post-secondary institutions, there is considerable research that indicates that students prefer courses with instructors that they perceive as being supportive. In such courses, students report that they participated in class activities, were willing to engage and talk in class, established rapport with instructors and classmates, and were less likely to disrupt the classroom or challenge the instructor. Further, not surprisingly, a positive relationship is reported between feeling "connected" in the classroom and student learning [6].

Ultimately, due to community being identified as essential when aiming to support collaboration and promote high levels of learning, there has been a movement toward more learner-centered experiences [7; 8]. Therefore, an appreciation of the importance of developing learning communities in postsecondary education environments has materialized [9; 10], as learning communities are built upon the notion of groups of students positively experiencing activities together and seeing learning benefits from doing so.

\subsection{Cohort learning groups}

One approach that has been considered, and ultimately embraced, by post-secondary institutions to aid institutional efficiency and effectiveness and to enhance the learning experiences of students has been the use of cohort learning groups. This has resulted in a marked increase in the practice of providing cohort-based learning opportunities for students in post-secondary environments since the early 1990s [11].

The literature categorizes cohort learning groups as being situations where students are intentionally placed in consistent groupings for their learning [10; 12] while also experiencing a common, sequential program of learning [11]. By doing so, such groupings allow for students to be involved in learning opportunities that include shared experiences, interactions, collective effort, and learning toward educational goals [12]. The practice of cohort groupings aims to utilize interpersonal relationships within the cohort membership to enhance the learning process and create opportunities for support [13; 14]; at the same time as assisting the promotion of intellectual and academic stimulation $[10 ; 14]$.

The benefits of cohort learning experiences are well documented in numerous studies. Such studies consistently report an enrichment of learning for the student cohort membership [12]. While there are some drawbacks noted in the literature, namely perceived tension, jealousy, and competition between members, the benefits of cohort experiences present compelling reasoning for the adoption of cohort programming in post-secondary educational environments [10, 12].

Benefits are not solely seen at the student level though. From an institutional perspective, the issue of retention of students in programming is something that institutional administrators face. Interestingly, the impact a high rate of student attrition of can be viewed in two very different ways. One view point is that attrition can indicate that there are high standards of performance required and successful students are considered or recognized as being well above average. However, a second, and very different, view point can potentially result in serious implications for institutions. When students do not succeed and rates of attrition are high, it is often accompanied by critique of instructional and student development priorities and can centre on the question of the financial expense to students. While institutions need to be cognizant of academic rigor and standards of achievement, the notion of admitting students in to programming knowing that a large portion will likely never finish does raise ethical questions for the institution and issues of value for the student. Therefore, the positive effect of cohort membership on student enrolment retention rate [10] is a most critical and important factor for institutional administrators to consider.

Also, from an institutional perspective, cohort programming provides an administrative ease of design and delivery [15] due to the use of a lock-step style of program scheduling. As administrators know and can plan a program from start to finish and the fact that all students require the same coursework, administrators have prior information on such issues as registration numbers, class sizes, room needs, and even text book ordering requirements. It creates greater predictability for institutional administrators. Interestingly, this has also been identified by students as being a positive feature as they find cohort programming to be easier to navigate, know and follow required processes and procedures, and understand pre-determined programming [16].

\subsection{Role of instructional staff in cohort learning groups}

In discussing the notion of developing a community of inquiry, researchers have identified three interdependent elements that are necessary to ensure a meaningful learning experience: social, teaching, and cognitive presence [17]. In particular, the teaching presence element describes instructional staff as being critical for success and the modeling and facilitative role that instructors play as being vital for student retention and progress. However, 
while research evidence has clearly shared the positive impact of cohort learning experiences from a student perspective, the majority of the research literature has not addressed one specific component of the overall cohort experience. It has neglected to understand the perspectives of the instructional staff members who teach the cohort learning groups.

Even though instructional staff members are viewed as being a part of the overall success of learning communities, little is known about the specific role that they play in this success or their perceptions of their role. Therefore, due to this distinct absence of an understanding of the role of instructional staff in a cohort experience, research is required to add to the literature and provide new knowledge on the cohort learning community from an instructional staff perspective.

\subsection{Summary}

Although there is much recorded positivity in terms of academic success, social support, and feelings of connectedness for students when participating in a cohort learning group experience, there may be other benefits or even issues specifically experienced by the instructional staff that teach the coursework to such cohorts of students. For example, the increase of student presence and voice that is often found in cohort learning groups may support instructors in creating conducive and engaging learning environments due to student readiness to participate in classroom activities or, conversely, may pose unique challenges to instructional staff due to students being too comfortable in offering overly-negative critique of the thoughts and ideas of others. Therefore, knowledge of the experiences and perspectives of instructional staff in a cohort experience is of value to the full understanding of cohort learning; it can complete the circle of understanding.

\section{Methodology}

The purpose of this research study was to investigate and begin to understand the perspectives of instructional staff members that teach students in a cohort learning community setting.

\subsection{Background information}

The cohort learning environment where the study was conducted was an established part of a collaborative programming experience between a large research intensive university and a small regional college in northern Canada. This joint venture was constructed in a manner that allowed the program participants to take all the required undergraduate course work at a local regional college while attaining a Bachelor of Education degree from the larger university. The program was designed to achieve two major benefits: first it allowed students to continue to live in their home community and undertake their undergraduate degree coursework without the need to move to a larger centre and, second, it aimed to create qualified, potential employees with community ties for regional employers.

Due to the uniqueness of the program at the regional college, the students experience their programming as part of a cohort that would be described as a restrictive closed-cohort [12]. As such, cohort members take the same courses as each other and in the same sequence and at the same time; thereby following a common community style class schedule that is consistent amongst all the students. Interestingly, this issue of community is even further extended as the cohort receives the vast majority of the courses in the program in a specially dedicated classroom. Therefore, students not only have a distinct familiarity with their classmates, but also with the physical classroom location.

\subsection{Research focus and questions}

Based on the identified lack of research understanding of the cohort experience from an instructional perspective, the research study was purposefully designed in a manner to investigate and consider the following two research questions:

1. What are the experiences of instructors when delivering coursework to a cohort of students?

2. How can instructors contribute to the student cohort experience?

\subsection{Research design}

The research study utilized action research as its methodology. Action research in education involves systematic inquiry to gather information about, and subsequently, improve the ways of operation, teaching, and how well students learn [18]. The study followed an outsider in collaboration with insider approach to the action research process [19]. This approach to action research requires that both the researcher and the participants to collaborate in order to understand issues and find answers to question(s) or problem(s).

As per the Action Research design, the research study had a series of repeated phases [initial, action, observation, reflection] with each phase consisting of a particular focus such as relationship building, the consideration and reflection on instructional practice, and planning future action. Action research data collection techniques can be categorized under three headings: experiencing (e.g. observations and field notes), enquiring (e.g. interviews and discussions), and examining (e.g. journals and personal reflections) [20]. Therefore, the research study 
utilized data collection techniques that fell under each of these categories.

The role of the researcher in this study was both a participant observer and a non-participant observer [18]. The participant observer role occurred during the planning, action, and reflection phases of the study. However, during the observation phases the researcher took on a non-participant observer role while taking field notes and recording observations. Consequently, the researcher met with participants, discussed their experiences, conducted individual informal interviews and small group discussion sessions, collected on-line individual reflections and compiled researcher notes throughout the research process. Throughout this process, the researcher posed probing style questions to clarify and seek elaboration of participants' responses as suggested by Patton [21]. The specific probes were designed to help clarify the understanding and interpretation of the data being provided and develop a deep understanding of instructor perspectives of their experiences of teaching a cohort learning community.

To enhance credibility and trustworthiness, several sources of validity were considered. Process validity to examine the adequacy of the processes used in the different phases of the study was continually established through the triangulation of journals, observations and interviews. Democratic validity, ensuring that all perspectives were considered, occurred through data gathering from individual interviews, and dialogic validity was enhanced through the continued intentional sharing of findings with the participants.

\subsection{Participants}

The variety of courses in the program provided to the cohort learning community was delivered by eight instructional staff members. All eight instructional staff members were invited to participate in the study. From this total of eight, seven agreed to do so, providing a participant pool representing $87.5 \%$ of the overall instructional staff.

All seven of the instructional staff participants had obtained a Bachelor of Education degree and a master's degree and several had earned a doctorate. All the participants had previous or current experience of teaching in the K-12 school system and of the teaching post secondary level course work. Of note is that the instructional staff participants had a range of previous experiences of teaching with cohort groups at the post-secondary level. One participant had taught more than 10 cohort groups, several had taught more than five cohort groups, one participant had taught a cohort group but at another educational institution, and another was completely new to the cohort experience and teaching to such a learning community of students. However, none of the participant instructors reported that they had personally experienced being part of a cohort learning community as learners themselves.

\subsection{Data collection}

Data were collected from a variety of sources. From this data it was possible to interpret and begin to understand the lived experience of the instructional staff members. The qualitative data collected were interpretationally analyzed. Analysis involved manual categorization through line-by-line coding of transcripts, interpretation of researcher interview notes, and participant reflections that identified salient meaning from the data. Such meaning was then grouped by content and themes and patterns were identified to describe, draw conclusions, and explain the phenomenon being studied [22].

\section{Results and Findings}

The findings of the data collected from the instructional staff participants indicated that they believed that their experiences of teaching within a cohort learning community were most beneficial. Interestingly, and of significant importance, they noted that these benefits were not only restricted to the student cohort community members but also applied to the instructors themselves.

In regards to the kind of benefits that the instructional staff members believed that the student cohort members experienced, they remarked that although there are always "...pockets of students..." that can challenge any teaching environment, they found that the cohort experience allowed students to “...do it together to extend learning..." and there was a "...power to the group..." that supported and aided student work habits. Comments were made that suggested that “...common goals...” resulted in opportunities for "...interactions for students with each other..." and that there was a "...shared motivation..." to achieve learning expectations or goals. These findings of increased learning opportunities and a supportive environment mirror the understanding gained by other researchers [e.g. $10 ; 13 ; 14 ; 16]$. Not surprising, the instructional staff participants overwhelming supported the value of a cohort learning experience and concluded that they believed that their own participation had also been most beneficial. As one participant remarked, " $A$ really, really worthwhile experience. I have become a better teacher. I find that I need to not only consider what I need to teach but also consider how might I support other instructors and how can they support me..."

The data collected in this study was rich and varied with many points of discussion. From this, three themes of experience for the participants were 
identified:

1. Developing the potential of the cohort.

2. Providing platforms for communication.

3. Recognizing the instructional team as a cohort.

\subsection{Theme: Developing the potential of the cohort}

In alignment with the strengths identified by others [e.g. 10; 13; 14], participant comments collected in personal interviews and group sessions identified that the cohort experience provided a level of collaboration and comfort for the students that supported learning experiences. Hence, it was believed that students were prepared to risk and sought support from each other. Example participant comments:

"Cohorts can provide opportunities due to trust, allegiance, and loyalties."

"Cohorts can present a different dynamic. There is a comfort to risk but also a concern to critique... collaboration is something that can be exploited with a cohort group."

It was also remarked by participants that it was critically important that the cohort members be given opportunities to learn how to function effectively as a group. To not limit the potential of the cohort, it was viewed as a weakness by the instructional staff to simply assume that students had this understanding. This was seen in such participant comments as:

"We cannot assume that students will become a cohort, we need to teach being a cohort...students need to learn to be in a cohort."

"...need to set the tone for the group...you belong to a cohort so you have responsibilities to yourself, the cohort, program, and profession...you are part of a club!"

"...students are getting something special...we need to let them know...need to be deliberate in letting students know what being in a cohort is..."

These comments illustrate that the instructional staff participants believe that cohorts have considerable potential but such potential needs to be drawn out of the group rather than simply expecting it to occur. That, according to the participants, is a key role that instructors can play; to support the realization and impact of the cohort.

Several participants commented that they or others, such as institutional leadership, could play a key role in informing students of what being in a cohort required. Specifically, they commented:

"Students don't start the program as a cohort...well they do physically, but not mentally, they have to learn to be a cohort. I see a big difference from early in the first term to later."

"The students need an orientation to start the year, a workshop perhaps on being a cohort member...a contributing member...what it entails...what to expect...how to be in a cohort...how to act...then refresher sessions at key points during the year. That way we can ensure that the experience works for everyone and they all get the benefits we hope can come from the experience."

"If students are alerted to what to look out for to know when and how to support others and how to reach out for support for themselves too, it would benefit them and, also, us!"

"If we or someone else, perhaps the cohort coordinator, don't do something formally we stand the chance of limiting the potential of the group and the overall cohort experience."

It was postulated by participants that such an approach could provide students with several key points of information:

"Students need to be oriented early to the benefits of being in a cohort...the expectations and how best to gain the most from the experience."

"...students need to understand that being a cohort member requires work to achieve the benefits of membership...feelings of trust and support only happen if they are prepared to immerse themselves in the membership experience."

"...in the same way, students need to be aware of the responsibilities that come with their cohort membership. They will need to be supportive of others...feel comfortable sharing the classroom with the voices and presence of others...be prepared to encourage the success of others."

With such an "orientation", one participant stated: "That is the only way we can say we are supporting the cohort otherwise we just hope that it works and that's not enough...we need to actively encourage...we need to lead students to become a cohort...it's like the cooperative learning thing...you can't just put kids in groups and expect cooperation...you have to teach it...well, the same goes for cohort membership...we need to teach it to our students...we need to be more intentional with it all."

It was also noted by participants that the benefits of students knowing how to be successful in a cohort learning group would extend beyond the students themselves and also result in advantages for the instructional staff too. They commented:

"Cohorts can provide me with opportunities to create a different dynamic in the classroom...there is a comfort level in students to risk that isn't always there in other classroom settings."

"We can intentionally exploit the level of collaboration...this is so important in a teacher ed. program where collaborative skills are a necessity to successful as a teacher in our schools."

"It is almost like we immerse the students in a professional development program before they are actually in the field...this enriches our classroom, the learning we can have...and helps me as an instructor 
to have the level of discussion and reflection that really matters for beginning educators."

Interestingly, participants raised the issue of responsibility for when things "go wrong" with the cohort. The participants questioned whether responsibility lay with individual instructors to work on issues, the instructional staff as a whole, or the coordinator.

"Just as much as we like things when they go well, we need to remember that sometimes it doesn't and some kind of intervention may be needed...Who should take on that responsibility? Is it me, all of us, or the coordinator...I'm not sure...perhaps it depends on the situation or circumstance...but it does need to be done and do we all need to know about it and what was done to help? I think we should."

This issue was one that the participants had not considered previously and just assumed that the coordinator would "look after things" and "do whatever was necessary". However, once raised, it quickly resulted in a joint agreement that a collective approach was required for full knowledge and understanding and any required consistency from instructors in their actions, teaching, or decision making.

"Consistency is a must for us; otherwise different things can happen in different courses. We run the risk of being inconsistent and sending the message that collectively as instructors we do not know what is happening. We stand the risk of being seen as individuals rather than a team"

"As it is the same group of students that we have it creates a shared understanding for us as instructors...both the good stuff and the not so good."

Overall, it was clear from the data that developing the potential of the cohort was a major consideration for the participants. They saw multiple benefits from doing so and believed that it was important to formally create a way to ensure that it was intentionally achieved.

\subsection{Theme: Providing platforms for communication}

Participants identified the importance for instructional staff to have the opportunity to meet as a group to discuss issues pertaining to cohort matters and their instructional practices. The instructional staff participants remarked that they believed that students often require assistance to deal with learning issues or those things that occur in day-to-day life outside of the learning environment. Lei et al. [10] suggested that the introduction of cohort learning experiences in post-secondary education settings was due to issues that included instructor isolation which can lead to a lack of effectiveness. The fostering of opportunities for communication between instructional staff could address such possible isolation and increase instructional effectiveness. As participants remarked:

"Discussing issues with someone else is helpful...I think others are probably experiencing the same kind of issues as we share the same group of students."

"We shouldn't be our own little islands; we need to come together... a bigger and collective island."

The data collected from the instructional staff participants indicated that increasing communication could support them as a group, provide for a better student experience, and illustrate to students that the instructional staff are a collective team. Example participant comments:

"Our teaching is not done in isolation...one body of students that we all share..."

"When other instructors discuss what they were seeing or experiencing, I understand that I could learn from their experiences too."

"...the instructional team needs to role model...we need to ensure that the instructional team speaks the same language."

"Most of the instructors share the same office, the same student group; can we not arrange times for us to share other issues too?"

Similar to Pemberton and Akkary [12] who suggested that cohorts provide opportunities for students to share experiences, the instructional staff participants also recognized the importance of sharing information amongst their own membership. As explained by two instructional staff participants: "...students know more than we do, they all experience the same things each day...they know what is going on, where I come in one day a week and know little of what has occurred since my last visit...”

"Finding ways to bring us together can provide a valued added experience for us all."

Therefore, communication between the instructional staff could increase information and understanding and decrease the isolation identified by Lei et al. [10]. Such sharing could also, according to the participants, provide a collective response to those students in need of support. This would negate the need for a student to inform a number of separate instructors the same set of information and provide the foundation for a collective, consistent and supportive response across all the members of the instructional team.

However, it was remarked by two participants that communication opportunities needed to extend beyond regular face-to-face meetings. For these participants, travelling to and from home to campus required considerable time. The participants remarked:

“...I appreciate opportunities to talk with others, I understand the importance of doing so and I want to, but the reality is that I only get paid for my teaching and my travel when I am teaching. If meetings are 
held on days when I am not teaching or are several hours after I have finished teaching, it causes me problems. When I have to come in to campus or stay on campus, it means I cannot do other things that I need to do for me."

"I would love to come in and meet but my other job just doesn't allow for that. I need my other job as teaching one course does not pay my bills, my other job does."

The issue of time and financial reimbursement was extremely important for these participants. Although the participants recognized the need and importance of communicating with others, the participants did suggest that there could be other ways to participate in such communication. For example:

“...we can use SKYPE or something similar to bring people to meetings”

"...can the coordinator place some key issues on a specially constructed on-line site where we can all check for important information and also add our thoughts and ideas?"

"...I would be glad to conference call in to meetings if it worked with my schedule, but I would need a few days to arrange things to ensure that it worked for me."

"We should be able to use technology to its fullest here to achieve what we are aiming for...I would be willing to look at what can work for us all."

The issue of communication was seen as critically important to all participants but the practicalities of attending a regular meeting was thought, by some, to be an obstacle that needed to be considered. Therefore, different technologies should be considered to support participation for those instructional staff members who are not able to physically be on campus and also facilitate the sharing of information and ideas amongst the instructional group.

\subsection{Theme: Recognizing the instructional team as a cohort}

Interestingly, over the time period of the study, the instructional staff participants came to the realization that they too needed to become a cohort. They expressed a need to find opportunities for reflection as an instructional team in order to share such things as instructional ideas or thoughts and, importantly, to develop and enhance relationships amongst the team members. Example participant comments regarding this thinking were:

"I've been thinking about this a lot lately...I believe that we really need to think of ourselves as a cohort too. Not really part of the student cohort but something like a partner or a co-cohort, one that can intersect when necessary but has its own identity. How can we not think that way?"
"I think we are a cohort in many ways, our own cohort...we haven't really formally acted like one in the past...in a coherent manner as such...we have informally discussed a few things. Maybe we need to think of ourselves as a cohort of instructors much more than we normally do. I think that if we did it would have a lot of benefits for everyone."

"We are [a cohort] whether we want to be or not as we have a common group of students."

Some participants expressed a belief that an informal instructional staff cohort may have occurred previously. However, it was thought that this was largely achieved without true intention and was not formalized in any way. This was expressed by one participant:

"I think we have acted as a cohort sometimes, well a few of us have, I think those of us who have been around for a while have become comfortable to share things with each other, like what is happening, etc. However, now that I am thinking about it, we really didn't do it with everyone; it was more like hallway conversations or the cross over between courses with one instructor leaving and the other coming in."

The need for adopting a more formal approach was expressed by the participants. Such a move was viewed to have the potential of allowing instructional staff to share ideas, thoughts, and best practices and to ensure that the learning environment is informed from all those that contribute to the student cohort experience. This notion is highlighted in the following comments:

"Perhaps it is just me but I have always wanted to be more than just an individual instructor...especially as we have a group of students that have common experiences. Surely, we need to talk to each other to ensure that we know what is going on in each other's classes. Isn't that good pedagogy?"

"We have a home room, but we also need a home room of teachers."

"Intentional is better than accidental or incidental."

"We need to organize ourselves to create our own professional learning community."

Participant remarks indicated that they believe that if the instructional staff members see themselves as a cohort, students would be positively impacted. This thought supports the work of Ford and Vaughn [23] who suggested that a bond or connection between instructors and students is necessary for a successful cohort experience. It was also evident that participants believed that formalizing the instructor group would have distinct benefits for the instructional staff too.

Therefore, the purposeful creation of an instructional staff cohort that could operate separately from and intersect with the student cohort could prove to be advantageous to the overall learning environment. 


\section{Discussion}

The findings from the study provide considerable thought on reasons why and how instructional staff members perceive that they can contribute to the cohort learning experience. Participants strongly recognized the value of the experience, appreciated the role that they play, and perceived that they can enhance the cohort learning experience for both the students and also themselves. It is clear from the data received that participants believe that they have a distinct role to play in a cohort learning community.

In regard to the research questions, analysis of the data has provided evidence that can answer or at least partially attend to each of the research questions.

1. What are the experiences of instructors when delivering coursework to a cohort of students?

Overall, the participants believe that the experience is positive and an enjoyable experience. As participants suggested:

"Not having taught a cohort before I really didn't know what to expect. I suppose some things were a surprise and others were what I expected. However, it has been really enjoyable. It is like being part of a family in many ways - there are ups and downs but generally it is much more personal than some of my other experiences."

"The cohort experience provides me with a license to try different things more than I would with a regular class...it enables me to create a better learning environment for the students."

Collectively, the participants believed that the experience of teaching courses with a cohort learning group enabled them to become better instructors and promoted a learning environment for students that supported a more in-depth consideration of issues. As remarked by one participant:

"Cohorts are like living animals...enables me to ask 'who pushes your thinking?' and allows me to teach beyond a superficial, pragmatic level and delve in to issues on a deeper level of understanding...I suppose that it helps me become a better teacher educator...it has improved me."

\section{How can instructors contribute to the student cohort experience?}

The instructional staff participants indicated that they believed that they have a distinct role to play in the cohort learning experience. For example, a participant remarked:

"We need to be able to come together on a regular basis. That way, we can support each other and also be a better team for the students. I will not be asking them to think one way and someone else the opposite."

\section{Conclusion}

This paper addresses a study that focussed upon the cohort learning environment from the perspectives of instructional staff members. From the data collected, it is evident that the instructional staff participants recognize and appreciate the uniqueness of the cohort experience and the benefits that it can bring not only students but also themselves.

The participants clearly believed that it is critically important that the potential of the cohort is intentionally sought, developed, and brought to the attention of the students. Failure to do so, it was thought, could easily result in experiences being less than desired. They also have articulated that in many ways that they see themselves as a possible cohort that can, at times, intersect and co-exist with the student cohort group. It was mentioned on numerous occasions by the instructional staff participants that, by assuming a cohort identity, they could become more: aware of specific issues with the student cohort group; cognizant of integrating teaching ideas from each other; able to share information between themselves; and, supportive of each other.

Although this study presents a number of important considerations, due to the limited body of research literature on instructor experiences in cohort learning settings, it is suggested that further study is needed. By doing so, it can be determined whether there is a consistency of findings or whether additional or contrary themes and information found.

Further research could also investigate how an instructional staff cohort might operate, as it is clear that the instructional staff participants in this study visualize a distinct role for instructors in the overall cohort experience supported through the intentional creation of an instructional staff cohort. The direction and coordination of such an instructor cohort and exactly what role and responsibilities it might require to be successful need to be a focus of potential future work. Further, it is important that future research also consider how institutions might support instructional staff members that teach in cohort learning environments. For example, should institutions ensure instructional staff recognize and understand how to assist students to gain full benefit of the cohort experience? Or, should time be made available and opportunities created for instructional staff to meet to discuss the cohort instructional experience?

At present, most understanding and subsequent thinking concerning cohort learning environments has centred on the student experience and the contributions that students make to each other. However, the findings from this study suggest that instructional staff also have a story to be told and they can help to complete the circle of understanding. 


\section{References}

[1] M. B. Kerby, K. R. Branham, and G. M. Mallinger, "Consumer-based higher education: The uncaring of learning”, Journal of Higher Education Theory and Practice, vol. 14, no. 5, pp. 42-54, 2014

[2] C. Hickson, "Completing the circle: Understanding the role and contribution of instructional staff in a cohort experience”, iCERi 2015 Proceedings, Seville, Spain, iated, 2015.

[3] L. Dyson and B. Hanley. "Testing the effect of a cohort grouping model as a form of instructional grouping in teacher education", The Canadian Journal of Higher Education, vol. 32, no. 2, pp. 27-46, 2002.

[4] J. J. Ponzetti, "Loneliness among college students", Family Relations, vol. 39, pp. 336-340, 1990.

[5] V. Jackson, "The use of a social networking site with pre-enrolled Business School students to enhance their first year experience at university, and in doing so, improve retention”, Widening Participation \& Lifelong Learning, vol. 14, pp. 25-41, 2013.

[6] S. A. Myers, and K. A. Rocca, "Perceptions of climate, apprehension, and state motivation”, Western Journal of Communication, vol. 65, no. 2, pp. 113-137, 2001.

[7] T. L. Doolen and E. Biddlecombe, "The impact of a cohort model learning community on first-year engineering student success", American Journal of Engineering Education, vol. 5 no. 1, pp. 27-40, 2014.

[8] M. Leisey, D. Mulcare, L. Comeford, and S. Kudrimoti, "Exploring team-based learning at a state university", Interdisciplinary Journal of Teaching and Learning, vol. 4, no. 3, pp. $172-185,2014$.

[9] M. Cleveland-Innes, R. Garrison, and E. Kinsel, E. "Role adjustment for learners in an online community of inquiry: Identifying the challenges of incoming online learners", in L. Tomei [Ed.]. Online and Distance Learning: Concepts, Methodologies, Tools and Applications. pp. 1814-1827. Hershey, PA: IGI Publishing, 2008.

[10] S. Lei, S., D. Gorelick, K. Short, L. Smallwood, and K. Wright-Porter, "Academic cohorts: Benefits and drawbacks of being a member of a community of learners”, Education, vol. 131, no. 3, pp. 497-504, 2011.

[11] D. W. Rausch, and E. K. Crawford, "Cohorts, communities of inquiry, and course delivery methods: UTC best practicum learning - The hybrid learning community model", The Journal of Continuing Higher Education, vol. 60, pp. 175-180, 2012.

[12] C. Pemberton, and R. K. Akkary, "A cohort, is a cohort, is a cohort...or is it?" Journal of Research on Leadership Education, vol. 5, no. 5, pp. 179-208, 2010.
[13] I. Saltiel, and C. S. Russo, Cohort Programming and Learning: Improving Educational Experiences for Adult Learners. Malabar, FLA: Krieger, 2001.

[14] K. Seifert, and D. Mandzuk, D. "Student cohorts in teacher education: Support groups or intellectual communities?” Teachers College Record, vol.108, no. 7, pp. 1296-1320, 2006.

[15] M. Nimer, "The Doctoral Cohort Model: Increasing Opportunities for Success", College Student Journal, vol. 4, pp. 1373 - 1379, 2009.

[16] C. H. Unzueta, W. Moores-Abdool, and D. V. Donet, "A different slant on cohorts: Perceptions pf professors and special education doctoral students", Presentation at American Educational Research Association, New York, USA: AERA, 2008.

[17] D. R. Garrison, T. Anderson, and W. Archer, The first decade of the community inquiry framework: A retrospective. The Internet and Higher Education, vol. 13, no. 1-2, pp. 5-9, 2010.

[18] J. W. Creswell, Research Design: Qualitative, Quantitative, and Mixed Methods Approaches, Thousand Oaks, CA: Sage Publications, 2014.

[19] K. Herr, and G. L. Anderson, The Action Research Dissertation, Thousand Oaks, CA: Sage Publications, 2005.

[20] G. E. Mills, Action Research: A Guide for the Teacher Researcher, Upper Saddle River, NJ: Pearson Education, Inc., 2003.

[21] M. Q. Patton, Qualitative Research \& Evaluative Methods: Integrating Theory and Practice. [4th Ed.]. Thousand Oaks, CA: Sage Publications Inc., 2014.

[22] M. Gall, J. Gall, and W. Borg, Education research: An introduction. [7th Ed.]. New York: Allyn and Bacon, 2003.

[23] L. Ford, and C. Vaughn, "Working together more than alone: Students evolving perceptions of self and community within a four-year educational administration doctoral cohort”, The Qualitative Report, vol. 16, no. 6, pp. 164-168, 2011. 